Kazukuni Araki MD, *

Ryoichi Nomura MD, *

Reiko Urushibara MD, *

Yukiko Yoshikawa MD, *

Yoshio Hatano MD $†$

\title{
Bronchial cuff pressure change caused by left- sided double-lumen endobronchial tube displacement
}

Purpose: The bronchial cuff pressures (BCPs) of left-sided double-lumen endobronchial tubes (DLTs) manufactured by Rüsch and Mallinckrodt were measured in 80 patients when the tubes were withdrawn to compare the effect of tube design on BCP change.

Methods: During general anesthesia with muscle relaxation, the cephalad surface of the endobronchial cuff was positioned either $2.5 \mathrm{~cm}$ distal to the carina (Rüsch Group R-l; $\mathrm{n}=20$ and Mallinckrodt Group B-l; $\mathrm{n}=20$ ) or just below the carina (Rüsch Group R- II; $n=20$ and Mallinckrodt Group B- I; $n=20$ ) and the cuff was inflated to $35 \mathrm{~cm} \mathrm{H}_{2} \mathrm{O}$. The tube was then withdrawn in $0.5-\mathrm{cm}$ steps until the cuff was $2.0 \mathrm{~cm}$ proximal to the cari$\mathrm{na}$, the position just before the capnogram or pressure-volume loop of tracheal lumen changed. The BCP at each step was measured. The rate of decrease in BCP was defined as the decrease of BCP divided by the length of displacement of DLT.

Results: The rates of decrease from the $+2.5 \mathrm{~cm}$ position to the end point in Group B-I $\left(7.7 \pm 0.8 \mathrm{~cm} \mathrm{H}_{2} \mathrm{O}^{\cdot \mathrm{cm}^{-}}\right.$ I) and those from the most proximal acceptable position to the end point in Group B-II $\left(19.5 \pm 4.8 \mathrm{~cm} \mathrm{H} \mathrm{H}_{2} \mathrm{O} \cdot \mathrm{cm}^{-}\right.$ I) were greater than those in Group R-I $\left(6.9 \pm 0.9 \mathrm{~cm} \mathrm{H}_{2} \mathrm{O} \cdot \mathrm{cm}^{-1}\right)(P<0.0 \mathrm{I})$ and in Group R-II $(I 2.4 \pm 3.1 \mathrm{~cm}$ $\left.\mathrm{H}_{2} \mathrm{O} \cdot \mathrm{cm}^{-1}\right)(P<0.0 \mathrm{I})$, respectively.

Conclusion: The BCP decreased in both of the Mallinckrodt and Rüsch DLTs, and the rates of decrease of the former were greater than those of the latter.

Objectif : Les pressions du ballonnet bronchique (PBB) des tubes à double lumière (TDL) gauches fabriqués par Rüsch et Mallinckrodt ont été mesurées chez 80 patients au moment du retrait des tubes afin de comparer l'effet du design du tube sur le changement de PBB.

Méthode : Pendant l'anesthésie générale avec myorelaxant, la partie supérieure du ballonnet endobronchique a été placée soit à $2,5 \mathrm{~cm}$ sous la carène (groupe Rüsch R-I; $n=20$ et groupe Mallinckrodt B-I; $n=20$ ), soit juste sous la carène (groupe Rüsch R-II; $n=20$ et groupe Mallinckrodt B- II; $n=20$ ) et le ballonnet a été gonflé jusqu'à obtenir une pression de $35 \mathrm{~cm} \mathrm{H} \mathrm{H}_{2} \mathrm{O}$. Le tube a été ensuite retiré par palier de $0,5 \mathrm{~cm}$ jusqu'à ce que le ballonnet soit à 2,0 cm au-dessus de la carène, la position occupée juste avant que ne change le capnogramme ou la boucle pression-volume de la lumière trachéale. La PBB a été mesurée à chaque palier. Le taux de baisse de PBB a été défini comme la baisse de PBB divisée par la longueur du déplacement du TDL.

Résultats : Les taux de baisse de pression à partir de la position $+2,5 \mathrm{~cm}$ jusqu'à la position finale du groupe BI $\left(7,7 \pm 0,8 \mathrm{~cm} \mathrm{H} \mathrm{H}_{2} \mathrm{O} \cdot \mathrm{cm}-\mathrm{I}\right)$ et à partir de la position la plus proximale possible jusqu'à la position finale dans le groupe $\mathrm{B}-\mathrm{II}\left(19,5 \pm 4,8 \mathrm{~cm} \mathrm{H} \mathrm{H}_{2} \mathrm{O} \cdot \mathrm{cm}-\mathrm{I}\right)$ ont été plus hauts que ceux des groupes $\mathrm{R}-\mathrm{I}\left(6,9 \pm 0,9 \mathrm{~cm} \mathrm{H} \mathrm{H}_{2} \mathrm{O} \cdot \mathrm{cm}-\mathrm{I}\right)$ $(P<0,0 I)$ et $\mathrm{R}-\mathrm{II}\left(\mid \mathrm{2}, 4 \pm 3, \mathrm{I} \mathrm{cm} \mathrm{H}_{2} \mathrm{O} \cdot \mathrm{cm}-\mathrm{I}\right)(\mathrm{P}<0,0 \mathrm{I})$, respectivement.

Conclusion : La PBB a diminué avec les TDL Mallinckrodt et Rüsch et le taux de baisse avec le premier a été plus marqué qu'avec le deuxième.

From the Departments of Anesthesiology, Ohtsu Red Cross Hospital, ${ }^{*}$ 1-1-35 Nagara, Ohtsu, Shiga 520-8511, Japan; and Wakayama Medical College, $\dagger$ Wakayama, Japan.

Address correspondence to: K. Araki MD. Phone: 81-77-522-4131; Fax: 81-77-525-8018.

Accepted for publication May 6, 2000.

CAN J ANESTH 2000 / 47: 8 / pp 775-779 


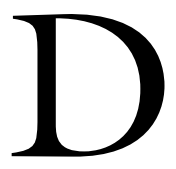

ISPLACEMENT of a left-sided doublelumen endobronchial tube (DLT) can be detected by monitoring the bronchial cuff pressure (BCP). ${ }^{1}$ This detection of displacement was previously assessed with DLTs manufactured by Rüsch. The design of the bronchial cuff of the DLT varies according to manufacturer (Figure 1) and the change in BCP may be affected by the design of the bronchial cuff. Thus, the aims of the present study were first, to determine if changes in BCP occurred in the DLT produced by another manufacturer, second to compare the changes in the BCP caused by displacement of left-sided DLTs produced by manufacturers, Rüsch and Mallinckrodt.

\section{Methods}

The study was approved by the ethics committee of our institution, and written, informed consent was obtained from each patient. Eighty adult patients who required one-lung ventilation were studied. We excluded patients with severe respiratory dysfunction and high risk patients. Patients were allocated randomly to one of two parts of the study.

In the first part of the study, anesthesia was induced with 1-2 $\mu \mathrm{g} \cdot \mathrm{kg}^{-1}$ fentanyl and $2-4 \mathrm{mg} \cdot \mathrm{kg}^{-1}$ thiopental and was maintained with fentanyl $(50-100 \mathrm{~g}$ bolus injection every hour) and enflurane (1-2\%) or isoflurane (0.7-1.5 \%) without nitrous oxide. Muscle relaxation was provided with vecuronium $(2-4 \mathrm{mg}$ bolus injection every 30-60 min) during the measurement and surgery. The left bronchus was intubated with either a left-sided Rüschelit ${ }^{\circledR}$ (Willy Rüsch $A G$, Kernen, Germany; Group R-I; $\mathrm{n}=20$ ) or a left-sided BronchoCath ${ }^{\circledR}$ (Mallinckrodt Medical, Athlone, Ireland; Group B-I; $n=20)$. Tubes of the two manufacturers were allocated alternately to the patients in the series of the study. The tube size (\# 37- or \#39-French) was chosen based according to the patient's height, sex, and the findings of the chest roentgenogram. With the aid of a fibreoptic bronchoscope (FOB), the bronchial cuff of the DLT was positioned so that the cephalad surface of the cuff was visualized just below the carina. ${ }^{2}$ This was designated the $0 \mathrm{~cm}$ position. Positive values represent more distal positions, while negative values represent proximal positions. The DLT was advanced $2.5 \mathrm{~cm}$ referring to a scale, that was taped to its external surface at the mouth. To confirm that the distal tip of the bronchial lumen of the DLT had also advanced $2.5 \mathrm{~cm}$, FOB was performed before and after advancing the DLT. The valve of the pilot balloon of the bronchial cuff was connected to an aneroid manometer (Mallinckrodt Medical, Athlone, Ireland) via a threeway stopcock followed by inflation of the bronchial cuff

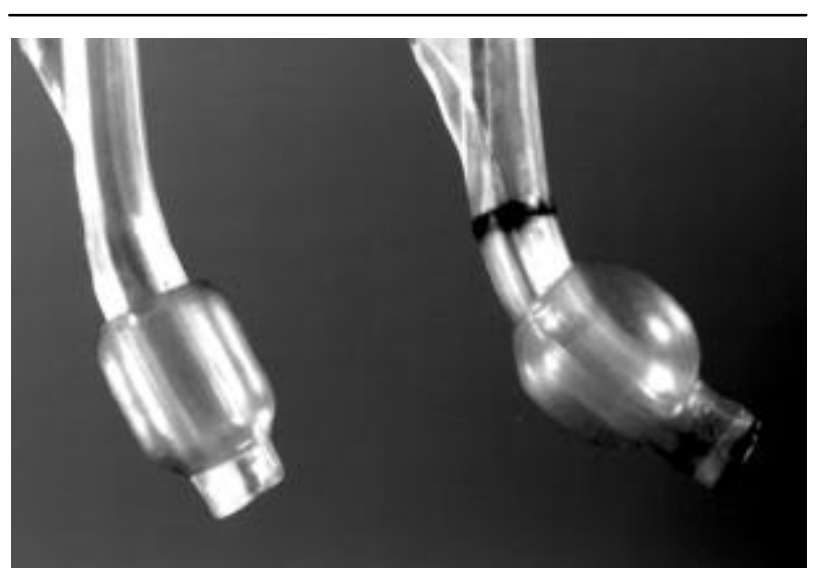

FIGURE 1 Bronchial cuffs of the left-sided double-lumen endobronchial tube manufactured by Rüsch (left) and Mallinckrodt (right).

with air at a pressure of $35 \mathrm{~cm} \mathrm{H}_{2} \mathrm{O}$ which is sufficient to seal the bronchus, ${ }^{3}$ and around which bronchial mucosal damage can be minimized. ${ }^{4-6}$ The volume of air injected into the cuff at this position was recorded. Two-lung ventilation was changed to right-sided, onelung ventilation with the minute volume of $0.1 \mathrm{~L} \cdot \mathrm{kg}^{-1}$ at a rate of $20 \mathrm{bpm}$. The left lung was insufflated with oxygen $100 \%$ throughout the measurements. The bronchial cuff was then withdrawn in $0.5-\mathrm{cm}$ steps referring to the scale taped to the DLT and the BCP was measured at each step. When the DLT was withdrawn to the $0 \mathrm{~cm}$ position, we confirmed that the bronchial cuff was just below the carina using a FOB. The BCP was recorded until the DLT reached the end point, which was the $-2.0 \mathrm{~cm}$ position, or the position that turned out to be the position just before the capnogram or the pressure-volume loop of the tracheal lumen, which was studied by using a respiratory monitor (ULTIMA SV, Datex Instrument Corp., Helsinki, Finland), changed from its initial value or configuration. To minimize the risk of bronchial mucosal damage during the measurements, the bronchial cuff was deflated each time the DLT was advanced or withdrawn and then was re-inflated with the same volume of air. These procedures were performed without disconnecting the syringe from the three-way stopcock, as described by Cox and Schatz. ${ }^{7}$ The rate of decrease in BCP was defined as the decrease of BCP divided by the length of displacement of DLT. Measurements were performed with the patient in the supine position without movement of the head or neck before surgery commenced. The patients were well paralyzed to avoid coughing during the measurements, but if coughing occurred, 
the measurement were paused and restarted from the beginning after sufficient muscle relaxation was obtained. Before each intubation, the length of bronchial cuff was measured when it was inflated with air to a pressure of $35 \mathrm{~cm} \mathrm{H}_{2} \mathrm{O}$.

In the second part of the study, the change in the $\mathrm{BCP}$ was analyzed specifically when the bronchial cuff was pulled into the trachea from the most proximal acceptable DLT position recommended by Benumof $e t$ $a l .^{2}$ Anesthesia was induced and maintained as in the first part of the study. The left bronchus was intubated with either a left-sided Rüschelit ${ }^{\circledR}$ (Group R-II; n $=20$ ) or a left-sided Broncho-Cath ${ }^{\circledR}$ (Group B-II; $\left.n=20\right)$. Either tube of the two manufacturers was allocated alternately to patients in this part of the study. With the aid of a FOB, the cephalad surface of the bronchial cuff was positioned just below the carina, and then the cuff was inflated with air to a pressure of $35 \mathrm{~cm} \mathrm{H}, \mathrm{O}$ at the $0 \mathrm{~cm}$ position. The volume of air injected into the cuff at the $0 \mathrm{~cm}$ position was recorded. The cuff pressure was then measured with every $0.5-\mathrm{cm}$ withdrawal from the $0 \mathrm{~cm}$ position to the end point, as in the first part of the study.

Data are presented as the mean \pm SD. Differences between the groups were determined using Analysis of
Variance or chi-square test for demographic and clinical data. Differences in the BCP within each group were determined using paired t test. $P<0.05$ was considered significant.

Results

There were no differences between the groups of patients in each part of the study with respect to age, height, weight, sex, tube size and side of operation (Table I). There was a tendency to greater length of the cuff in Rüschelit ${ }^{\circledR}$ groups than in Broncho-Cath ${ }^{\circledR}$ groups but the difference was not significant in either part of the study (Table I). There was a tendency to greater volume of air injected into the cuff in the Rüschelit ${ }^{\circledR}$ groups than in the Broncho-Cath ${ }^{\circledR}$ groups; the difference was significant $(P<0.05)$ in the first part of the study but not in the second part of the study (Table I).

In all patients the pressure progressively decreased as the DLT was withdrawn (Figure 2). The BCPs at end points were lower than the initial BCPs $(35 \mathrm{~cm}$ $\left.\mathrm{H}_{2} \mathrm{O}\right)$ in all groups of patients $(P<0.01)$.

The rates of decrease from the $+2.5 \mathrm{~cm}$ position to the end point in Group B-I and those from the $0 \mathrm{~cm}$ position to the end point in Group B-II were greater

TABLE I Patient characteristics. Values are mean \pm SD or $n$ of patients.

\begin{tabular}{lllll}
\hline & \multicolumn{2}{c}{ First part } & \multicolumn{2}{c}{ Second part } \\
& $\begin{array}{l}\text { Group } R-I \\
(n=20)\end{array}$ & $\begin{array}{l}\text { Group B- } I \\
(n=20)\end{array}$ & $\begin{array}{l}\text { Group } R \text { - II } \\
(n=20)\end{array}$ & $\begin{array}{l}\text { Group } \text { B- II } \\
(n=20)\end{array}$ \\
\hline Age $(\mathrm{yr})$ & $42.5 \pm 19.3$ & $47.5 \pm 21.8$ & $45.8 \pm 21.7$ & $49.1 \pm 20.0$ \\
Height $(\mathrm{cm})$ & $170.6 \pm 9.4$ & $167.6 \pm 9.1$ & $167.4 \pm 9.5$ & $167.8 \pm 8.0$ \\
Weight $(\mathrm{kg})$ & $60.6 \pm 9.2$ & $57.9 \pm 10.8$ & $58.2 \pm 8.7$ & $59.0 \pm 11.5$ \\
Sex $($ Male/Female) & $18 / 2$ & $19 / 1$ & $16 / 4$ & $18 / 2$ \\
Tube size (37/39 French) & $5 / 15$ & $3 / 17$ & $7 / 13$ & $3 / 17$ \\
Side of operation (Right/Left) & $10 / 10$ & $9 / 11$ & $10 / 10$ & $11 / 9$ \\
Length of bronchial cuff $(\mathrm{cm})$ & $1.97 \pm 0.19$ & $1.84 \pm 0.19$ & $1.96 \pm 0.21$ & $1.85 \pm 0.27$ \\
Volume of bronchial cuff $(\mathrm{ml})$ & $1.01 \pm 0.32^{*}$ & $0.81 \pm 0.25^{*}$ & $1.15 \pm 0.33$ & $1.03 \pm 0.29$ \\
\hline
\end{tabular}

Volumes of Bronchial Cuff were measured at the $+2.5 \mathrm{~cm}$ and $0 \mathrm{~cm}$ position in the 1 st and $2 \mathrm{nd}$ part, respectively $(\mathrm{ml}) .{ }^{*} P<0.05$, Group R- I vs Group B- I .

TABLE II Decreases in bronchial cuff pressures and rates of decreases in bronchial cuff pressure.

\begin{tabular}{lllll}
\hline & & $+2.5 \mathrm{~cm}$ to End Point & $+2.5 \mathrm{~cm}$ to $0 \mathrm{~cm}$ & $0 \mathrm{~cm}$ to End point \\
\hline Group R- I & Decrease $\left(\mathrm{cm} \mathrm{H}_{2} \mathrm{O}\right)$ & $28.2 \pm 1.8$ & $17.9 \pm 5.6$ & $10.3 \pm 5.5 \dagger$ \\
Group B- I & Rate of Decrease $\left(\mathrm{cm} \mathrm{H} \mathrm{H}_{2} \mathrm{O} / \mathrm{cm}\right)$ & $6.9 \pm 0.9^{*}$ & $7.1 \pm 2.2$ & $6.3 \pm 3.4 \dagger$ \\
& Decrease $\left(\mathrm{cm} \mathrm{H}_{2} \mathrm{O}\right)$ & $29.1 \pm 2.7$ & $20.6 \pm 5.1$ & $8.5 \pm 4.7 \dagger$ \\
Group R- II & Rate of Decrease $\left(\mathrm{cm} \mathrm{H} \mathrm{H}_{2} \mathrm{O} / \mathrm{cm}\right)$ & $7.7 \pm 0.8^{*}$ & $8.2 \pm 2.0$ & $7.0 \pm 3.4 \dagger$ \\
& Decrease $\left(\mathrm{cm} \mathrm{H}_{2} \mathrm{O}\right)$ & - & - & $21.6 \pm 4.4 \dagger$ \\
Group B- II & Rate of Decrease $\left(\mathrm{cm} \mathrm{H} \mathrm{H}_{2} \mathrm{O} / \mathrm{cm}\right)$ & - & - & $12.4 \pm 3.1 \ddagger \dagger$ \\
& Decrease $\left(\mathrm{cm} \mathrm{H}_{2} \mathrm{O}\right)$ & - & - & $21.9 \pm 5.6 \dagger$ \\
& Rate of Decrease $\left(\mathrm{cm} \mathrm{H} \mathrm{H}_{2} \mathrm{O} / \mathrm{cm}\right)$ & - & $19.5 \pm 4.8 \ddagger \dagger$ \\
\hline
\end{tabular}

Values are mean \pm SD. ${ }^{*} P<0.01$, Group R- I $v s$ Group B- I. $\ddagger P<0.01$, Group R- II $v s$ Group B- II. $\dagger P<0.01$, First part $v s$ second part of the study. 
TABLE III Distribution of the positions at which pressure-volume loops deformed in each group of patients.

\begin{tabular}{lllll}
\hline DLT Position (cm) & -1.0 & -1.5 & -2.0 & No change \\
\hline Group R- I & 1 & 1 & 11 & 7 \\
Group B- I & 3 & 5 & 9 & 3 \\
Group R- II & 0 & 0 & 9 & 11 \\
Group B- II & 1 & 12 & 7 & 0 \\
\hline
\end{tabular}

The end points in Group B- I and Group B- II were significantly more distal than those in Group R- I $(P<0.05)$ and Group R- II $(P<0.01)$, respectively. The distributions of end points in Group R- I and Group B- I were not significantly different from those in Group R- II and Group B- II, respectively. DLT = double-lumen endobronchial tube.

than those in Group R-I $(P<0.01)$ and in Group R-II $(P<0.01)$, respectively (Table II). There were no differences between the rates of decrease from the +2.5 $\mathrm{cm}$ to the $0 \mathrm{~cm}$ position and those from the $0 \mathrm{~cm}$ position to the end point in Group R-I and Group B-I.

The rates of pressure decrease caused by withdrawal from the $0 \mathrm{~cm}$ position to the end point in Group R-II and Group B-II were greater than those in Group R-I and Group B-I, respectively $(P<0.01)$. No change in capnogram was observed in any patient of the four groups. The distribution of the positions just before pressure-volume loops deformed in each group of the patients is shown in Table III. The end points in Group B-I and Group B-II were more distal than those in Group R-I $(P<0.05)$ and Group R-II $(P<0.01)$, respectively. The distributions of end points in Group R-I and Group B-I were not different from those in Group R-II and Group B-II, respectively (Table III). The BCPs at end points in the second part of the study were significantly greater than those in the first part both in Broncho-Cath ${ }^{\circledR}$ and Rüschelit ${ }^{\circledR}$ groups $(P<$ $0.01)$.

\section{Discussion}

There has been some argument as to whether a FOB should be routinely used to position DLTs and to monitor DLT position during one-lung ventilation. ${ }^{8}{ }^{89}$ In the clinical setting, fibreoptic bronchoscopy cannot be performed continuously to monitor the position of the DLT throughout surgery. In contrast, BCP monitoring can be used to detect displacement of the DLTs continuously, and is more sensitive and easier than monitoring the pressure-volume loop or capnogram. ${ }^{1}$

The size and shape of the bronchial cuff may affect the change in the BCP caused by displacement of the DLT. In the first part of the study, the rates of decrease to the end point in BCP of Broncho-Cath ${ }^{\circledR}$ were

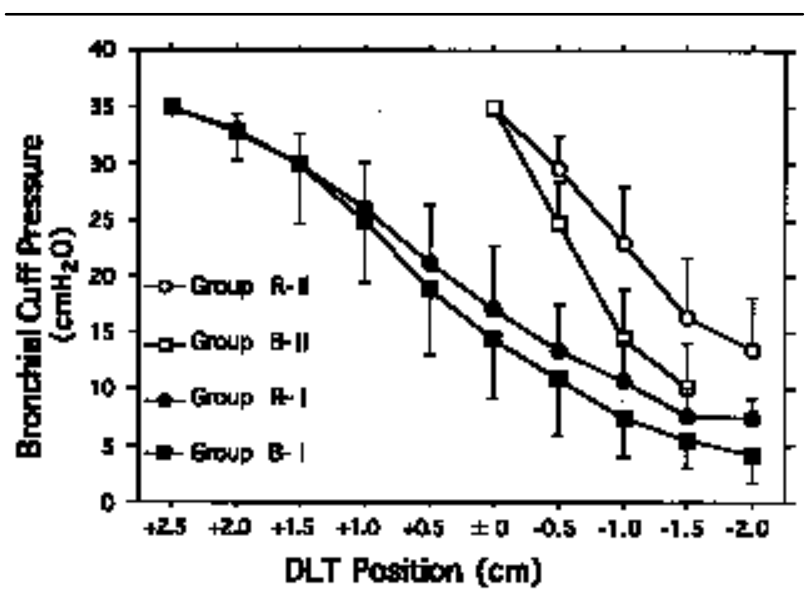

FIGURE 2 Bronchial cuff pressure change caused by DLT displacement. The bronchial cuff pressures at end points were significantly lower than the initial bronchial cuff pressures $\left(35 \mathrm{~cm} \mathrm{H}_{2} \mathrm{O}\right)$ in all groups of patients $(P<0.01)$.

greater than those of Rüschelit ${ }^{\circledR}$. The greater volume of air required to inflate the cuff to $35 \mathrm{~cm} \mathrm{H}_{2} \mathrm{O}$ in the Rüschelit ${ }^{\circledR}$ tubes may have blunted the response of the BCP to DLT displacement. Although both cuffs have similar sealing performance with very low cuff pressures, the bronchial cuff of the Broncho-Cath ${ }^{\circledR}$ tends to assume a "donut" configuration, while that of Rüschelit ${ }^{\circledR}$ has a "rolling-pin" shape. ${ }^{3}$ The latter allows pressure to be distributed over a greater surface, ${ }^{10}$ which may also have blunted the response of the BCP to DLT displacement.

In the clinical setting, monitoring the $\mathrm{BCP}$ during one lung ventilation, the greater the decrease of the $\mathrm{BCP},{ }^{10}$ the more likely is the bronchial cuff to have been withdrawn from the initial position, and also the seal of the bronchial cuff to be lost. In the present study, we found that the position at which sealing of the bronchial cuff was lost in the group of BronchoCath ${ }^{\circledR}$ was more distal than in the Rüschelit ${ }^{\circledR}$ group. Thus a greater BCP is necessary to seal the bronchus with the Broncho-Cath ${ }^{\circledR}$ than with the Rüschelit ${ }^{\circledR}$ tube if the bronchial cuff is withdrawn to the same extent. However, the mean BCPs required to achieve clinical one-lung isolation for Rüschelit ${ }^{\circledR}$ and Broncho-Cath ${ }^{\circledR}$ tubes when the proximal edge of the bronchial cuff was just below the carina were similar, $14.1 \mathrm{~cm} \mathrm{H}_{2} \mathrm{O}$ and $17.6 \mathrm{~cm} \mathrm{H}_{2} \mathrm{O}$, respectively. ${ }^{3}$

It is speculated that the earlier change in the pressure-volume loop would be caused by the shorter length or diameter of the bronchial cuff than the longer one or by the smaller surface area of the 
bronchial cuff in contact with the bronchial mucosa than the greater one. The smaller volume of the bronchial cuff in Broncho-Cath ${ }^{\circledR}$ than in Rüschelit ${ }^{\circledR}$ must have resulted in the earlier change in pressurevolume loop. Even in such Broncho-Cath ${ }^{\circledR}$ groups, the cuff pressures decreased before pressure-volume loops changed, which implies that BCP monitoring detects displacement of the DLT much earlier than do pressure-volume loops.

Although lateral positions reflect more clinical setting than supine positions, the latter were taken in the present study because incremental displacement and repositioning of the DLT can be performed with less difficulty and more safety.

It is recommended that DLTs are positioned so that the proximal edge of the bronchial cuff is just below the carina, ${ }^{2}$ or several millimeters below the carina. ${ }^{9}$ In the present study changes in BCP were observed whichever position was used. Thus, a change in BCP during surgery suggests DLT displacement, and it is highly recommended that the position of the DLT be monitored by BCP manometry.

In conclusion, we observed significant decrease in BCP caused by displacement of Broncho-Cath ${ }^{\circledR}$ as well as Rüschelit ${ }^{\circledR}$ endobronchial tubes. The rates of decrease in BCP of Broncho-Cath ${ }^{\circledR}$ were greater than those of Rüschelit ${ }^{\circledR}$. We recommend that BCP should be monitored throughout the operation whichever manufacturer you may choose.

\section{References}

1 Araki K, Nomura R, Urushibara R, Yoshikawa $\Upsilon$, Hatano $\Upsilon$. Displacement of the double-lumen endobronchial tube can be detected by bronchial cuff pressure change. Anesth Analg 1997; 84: 1349-53.

2 Benumof JL, Partridge BL, Salvatierra C, Keating J. Margin of safety in positioning modern double-lumen endotracheal tubes. Anesthesiology 1987; 67: 729-38.

3 Slinger PD, Chripko D. A clinical comparison of bronchial cuff pressures in three different designs of left double-lumen tubes. Anesth Analg 1993; 77: 305-8.

4 Seegobin RD, van Hasselt GL. Endotracheal cuff pressure and tracheal mucosal blood flow: endoscopic study of effects of four large volume cuffs. BMJ 1984; 288: 965-8.

5 Lewis FR Jr, Schlobohm RM, Thomas AN. Prevention of complications from prolonged tracheal intubation. Am J Surg 1987; 135: 452-7.

6 Joh S, Matsuura H, Kotani $\Upsilon$, et al. Change in tracheal blood flow during endotracheal intubation. Acta Anaesthesiol Scand 1987; 31: 300-4.

7 Cox PM Jr, Schatz ME. Pressure measurements in endotracheal cuffs: a common error. Chest 1974; 65: 84-7.
8 Benumof JL. The position of a double-lumen tube should be routinely determined by fiberoptic bronchoscopy. (Editorial) J Cardiothorac Vasc Anesth 1993; 7: 513-4.

9 Brodsky JB. Fiberoptic bronchoscopy should not be a standard of care when positioning double-lumen endobronchial tubes. (Letter) J Cardiothorac Vasc Anesth 1994; 8: 373-5.

10 Brodsky JB, Adkins MO, Gaba DM. Bronchial cuff pressures of double-lumen tubes. Anesth Analg 1989; 69: 608-10. 